\title{
Advanced Monitoring of Rail Cracks using LASER-EMAT System
}

\author{
Vishesh $\mathbf{S}^{1}$, Manu Srinath ${ }^{1}$, Shruthi Sreeram ${ }^{2}$, Pratheek Jayanth ${ }^{2}$, Samarth Bharadwaj D D ${ }^{3}$, \\ Sanjeev Sanjee Venkatachalapathi ${ }^{3}$
}

B.E, Department of Telecommunication Engineering, BNM Institute of Technology, Bangalore, India ${ }^{1}$

B.E, Department of Electronics and Communication Engineering, BNM Institute of Technology, Bangalore, India ${ }^{2}$

B.E, Department of Information Science Engineering, BNM Institute of Technology, Bangalore, India ${ }^{3}$

\begin{abstract}
Indian Railways is one of the largest railway passenger modes of transport in the world and is the backbone of the Indian transport infrastructure. However in terms of safety parameters and reliability we have not reached the global standards yet. The major rail accidents occur due to derailment of trains which are caused due to fault in the railway tracks. In this paper, we present to you a LASER pulse-EMAT crack detection system. The location and severity of the crack can be easily sent to the server or cloud storage, for necessary action. LASER pulse is incident on the track twice, after sometime on the same location for more precise monitoring of the tracks. This system can save many lives, by preventing major derailments of trains, in a country where rail accidents have become quite frequent.
\end{abstract}

Keywords: Safety Parameters, Reliability, LASER Pulse-EMAT Crack Detection System, Server, Cloud Storage, Ultrasonics.

\section{INTRODUCTION}

The Indian Railway network has a track length of 113,617 kilometres over a route of 63,974 kilometres and 7,083 stations. [1] It is the fourth largest railway network only exceeded by those of America, Russia and China. [2] The rail network is spread across the country and is known to carry around 30 million passengers and 2.8 million tons of freight daily. [3] In the six year period between 2009-10 and 2015-16, there were totally 803 accidents in the Indian railway killing 620 people and injuring 1855 people. $47 \%$ of these accidents were due to derailment of trains. [4] Figure 1 shows the percentage of accidents by type in the Indian Railways (2009-10 to 2014-15). [5] These derailments are caused mostly due to unattended cracks on the railway track. The trains of the Indian Railway are clocking more passenger kilometres each year. The number of casualties per million passengers carried is also increasing. From 3613 million passengers in 1980-81, the number of originating passengers reached 8224 million in 2014-15. [6] Figure 2 shows casualties per million passengers carried. [7] Many methods have been used to monitor the cracks in the railway tracks.

They are:

- Ultrasonic testing techniques

- Eddy current testing technique

- Joint bar inspection

- Automated tie inspection

- Rail grinding

Each of the above techniques has been explained briefly in the next section.

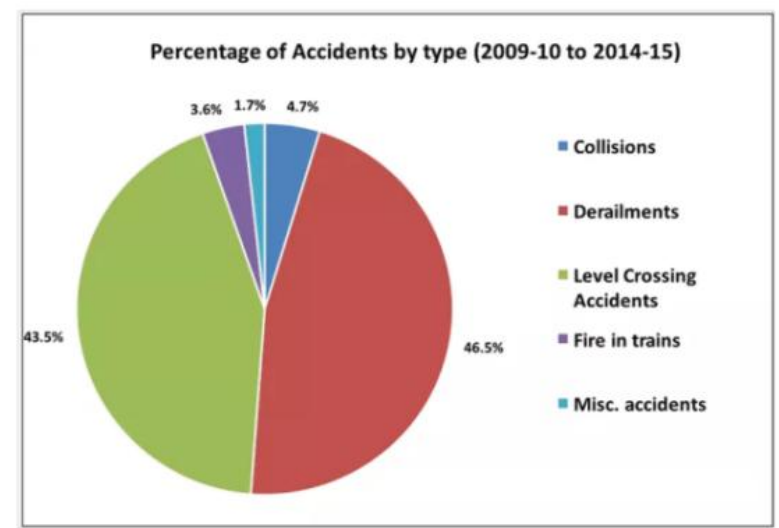

Figure 1 Percentage of Accidents by type

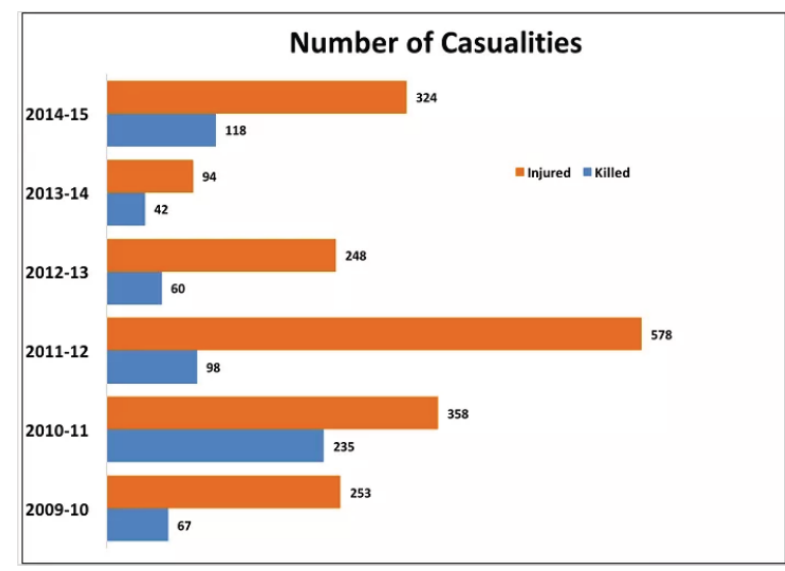

Figure 2 Casualties per million passengers carried 
Vol. 5, Issue 12, December 2016

\section{TECHNOLOGIES TARGETING RAIL CAUSES}

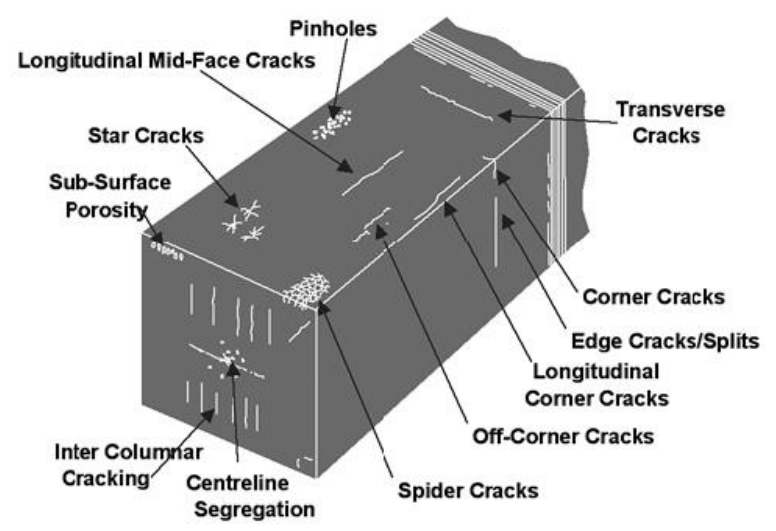

Figure 3 Instances of defects found on the surface and inside the railway track

Fracture occurs after sufficient propagation of cracks originating at: sites of manufacturing defects, such as inclusions; from rail head surface damage; from wheel burns; or from small rail head surface cracks which develop as a result of rolling contact fatigue. Figure 3 illustrates instances of defects found on the surface and inside a railway track. Below are the various methods for track monitoring:

A. Ultrasonic Testing Techniques: Conventional Contact Systems

The ultrasonic flaw detection technique involves introducing ultrasound - sound waves at frequencies above audible wavelengths - into the rail head which then propagate linearly through the rail steel until reflected entirely, or otherwise deflected, when encountering an internal defect or crack. The ultrasound waves are typically generated within a transducer held in close proximity to the rail head surface and transferred into the rail steel through an acoustic coupling medium such as water or other suitable liquid. Another ultrasonic transducer, also acoustically coupled to the rail surface, is used to detect echoes. Ultrasonic techniques are capable of detecting the presence of cracks and internal defects which cannot be detected visually. Much of the ultrasonic rail flaw testing being applied on North American railroads is contracted out by the railways to companies which offer specialized detection services. Sperry Rail Service, DAPCO Technologies, LLC (now owned by NORDCO Inc.) and Herzog Services Inc. are examples of companies which supply and operate self-propelled and/or hirail vehicles fitted with automated ultrasonic rail inspection equipment and staffed by skilled technicians. Testing normally proceeds at speeds between 15 and $20 \mathrm{mph}$ and the vehicle is stopped when defects are detected so that the rail can be examined in more detail and appropriate action taken. Some railways use non-stop test procedures, where one or more following vehicles stop to investigate the defect locations in more detail.

Although conventional ultrasonic rail testing techniques are used very effectively, they can be problematic to apply in situations where the rail head's surface condition is extensively damaged or significantly worn from its original profile thus making it difficult to maintain adequate acoustical contact with the rail head probes.

\section{B. Eddy current Testing Techniques}

Eddy current testing is an inherently non-contact technology which has been used extensively in industries such as aerospace and pipeline but until quite recently has not been applied to commercially viable rail testing. In this technique, the material to be tested is subjected to a magnetic field and the presence of surface cracks is inferred by observing the disruptions they induce in the magnetic field as measured by sensitive probes. A prototype mobile system for eddy current testing of rail, DYNATRAK II, was developed and tested in Canada. In that system, the eddy current probes were attached to a small carriage which was towed behind a hi-rail vehicle containing the electronic and power subsystems.

BAM, the German Federal Institute for Materials Research and Testing, in conjunction with German Railways, has been actively researching the application of eddy current testing to in-situ rail and several systems are now being used in Europe. Speno International has recently integrated an eddy current rail testing system called the HC Grinding Scanner onto a rail grinding machine.

This system is able to effectively detect and quantify the depth of head checking cracks using a set of four eddy current probes above each rail head. Eurailscout, a provider of rail testing services in Europe, owns and operates the self propelled rail test vehicle UST 02which combines ultrasonic and eddy-current testing techniques to detect head checks, squats and welds. Their system operates at speeds up to $70 \mathrm{~km} / \mathrm{h}$.

\section{Joint bar inspection}

Joint bars are typically visually inspected for any evidence of cracks, loose or missing bolts or other signs of movement. Inspections conducted on foot can be quite thorough although very time consuming, so this task is often performed by a track inspector travelling in a hi-rail vehicle. However, the vantage point from within a hi-rail vehicle is not ideal and those inspections are not as effective. Emerging technology seems promising for automating the visual joint bar inspection process. A prototype system mounted onto a hi-rail vehicle was jointly developed by the FRA and ENSCO, Inc. and field tested in 2005.49,50 at that time, the system exhibited a $60 \%$ false alarm rate while missing $15 \%$ of existing cracks, although it was noted that no centre cracks were missed.

\section{Automated Tie Inspection}

Traditionally railroad ties are inspected by workers who walk the tracks and visually inspect ties for problems such as excessive cracks, missing pieces and fastener condition. Digital imaging technologies are also very applicable for use in automating the railroad tie inspection process. 


\section{E. Rail Grinding}

Rail grinding is a maintenance process used by railroads for many years to refurbish the running surfaces of rail used in mainline track, switches and crossovers in order to prolong track service life. Wear at the wheel/rail interface which occurs during rolling contact and variability in the profile of the wheels of equipment travelling over the rails contribute to a gradual change in the shape of the rail head over time. These gradual changes in rail head shape lead to a shift in the location where the wheel surface contacts the rail head thus increasing contact stresses and the rolling contact fatigue which leads to the development of surface cracks which tend to propagate into surface defects such as shells or less frequently grow more deeply into the rail head and compromise the strength of the rail. Rail grinding is used to both reshape the rail head surface so that it matches the desired profile while removing the surface layer of fatigued material.

\section{III.METHODOLOGY}

Figure 4 shows the block diagram of the crack detection system in the railway track. A particular length of the railway track is made to carry ultrasonic sound waves by incidence of the LASER pulse on it. It traverses a distance of ' $\mathrm{x}$ ' before being detected by EMAT system to detect ultrasonics. EMAT is an ultrasound, non destructive testing (NDT) method which does not require a contact or coupling device because the sound is generated within the material adjacent to the transducers. EMAT can also be used for thickness measurement and material property characterization. Figure 5 shows how LASER-EMAT system is fixed beside the wheels/rims of the train/test vehicle. Firstly, a particular region of the track is exposed to LASER-EMAT system to detect critical points or cracks. In the proposed system, the region which was exposed ' $n$ ' seconds ago is again exposed at ' $n+t$ ' seconds. This is to cross verify the results obtained after the first incidence. Double checking is done to improve the accuracy of flaw detection.

Consider figure 6 where a particular length of track has developed a crack. LASER-EMAT system is deployed and ' $\mathrm{x}$ ' is a distance or region where ultrasonics are passed along the track (also inside the track) at one instance. The ultrasonics are produced by LASER pulses incident on the railway track. The presence of the crack like defect can be detected by a sudden change in the ultrasonic wave or by enhancement in the frequency content of the wave when pulsed LASER is incident on the railway track.

EMATs are placed at a certain distance ' $x$ ' from the incident LASER to allow the vibration to traverse through a region/distance before being received by transducers, which detects the reception of the ultrasonics and produces results. Figure 7 shows the output of EMAT with and without cracks along the track. As soon as the crack is detected, GPS location is received and the severity of the crack is colour coded and displayed. Also, the output is sent to the cloud for storage or real time study of flaws in the track.

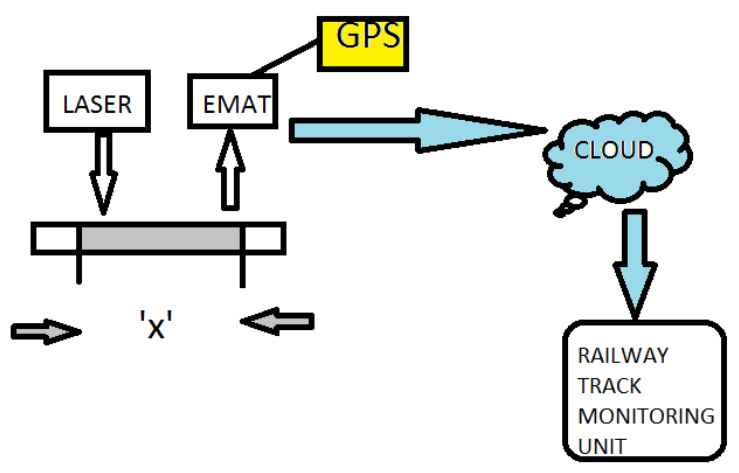

Figure 4 Block diagram of crack detection system

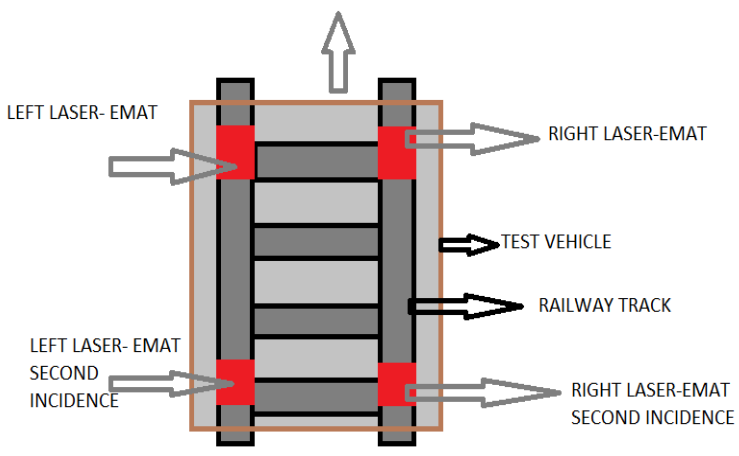

Figure 5 LASER-EMAT system fixed beside the wheels/rims of the train/test vehicle

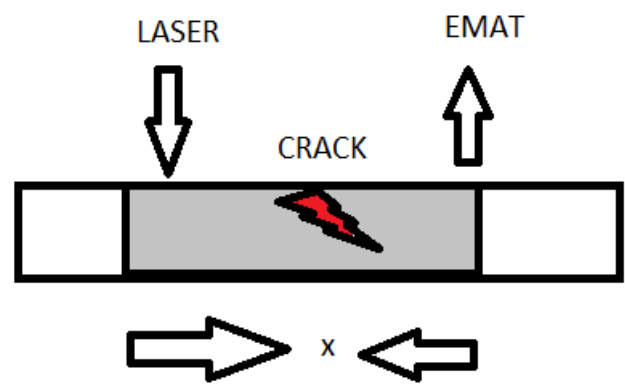

Figure 6 Length of track that has developed a crack

\section{IV.CONCLUSION}

India is the second most populous country in the world. Due to its huge landscape and population, there is a demand for a cheap and efficient means of transport. Railways is the right means of transport which fulfils the above two requirements. But the number of accidents due to derailment is quite frequent and tragic. Figure 8 and figure 9 draws limelight on newspaper articles in the CNBC $\left(21^{\text {st }}\right.$ November, 2016) and Hindustan Times website $\left(20^{\text {th }}\right.$ November, 2016). In this paper, we have proposed a LASER-EMAT system to combat the accidents occurring due faulty tracks leading to derailments of trains. 


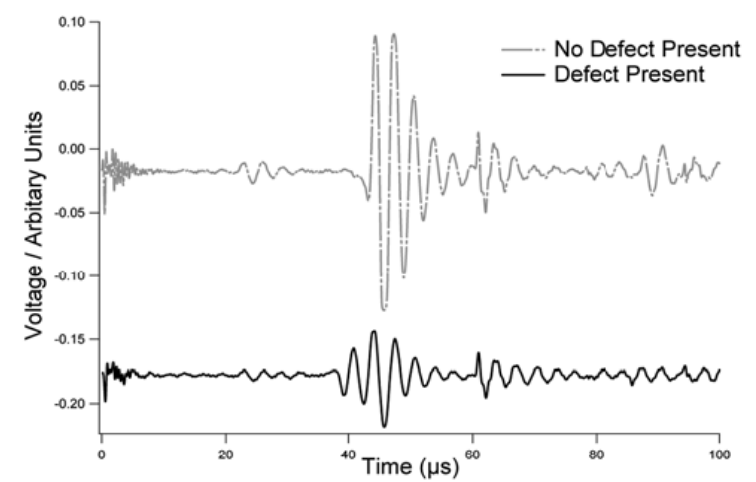

Figure 7 Output of EMAT with and without cracks along the track

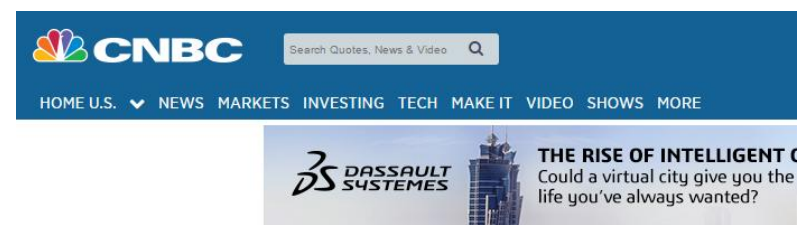

ASIA-PACIFIC NEWS

India rail crash raises concerns of underinvestment as death toll hits 146

\section{(9) REUTERS}

Figure 8 Newspaper article titled "India rail crash raises concern of underinvestment as death toll hits 146 " in the

CNBC website published on $21^{\text {st }}$ November, 2016

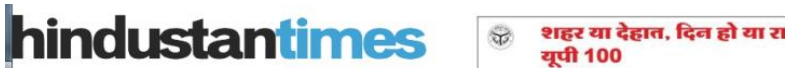

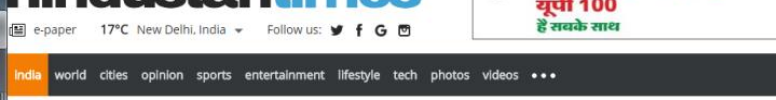 \\ Cracked tracks may have caused Indore-Patna train to derail, probe ordered \\ (iti)}

Figure 9 Newspaper article titled "Cracked tracks may have caused Indore-Patna train to derail, probe ordered" in the Hindustan Times website published on $20^{\text {th }}$ November, 2016

\section{REFERENCES}

[1] "Times of India". The Times of India. India. 15 April 2010

[2] Ministry of Railways. "Outcome, and Performance Budget of Railways for 2016-17" (PDF). Indian Railways. Retrieved 26 September 2016.

[3] http://indianrailways.gov.in/railwayboard/uploads/directorate/stat_e con/IRSP 2013-

14/pdf/Statistical_Summary/Summary\%20Sheet_Eng.pdf

[4] http://www.core.indianrailways.gov.in/

[5] https://www.thequint.com/india/2016/11/21/in-past-six-yearsindian-railways-accidents-killed-620-people-kanpur-uttar-pradeshindore-patna-express-derailment

[6] https://factly.in/indian-railway-accidents-statistics-review-last-5years/

[7] https://factly.in/indian-railway-accidents-statistics-review-last-5years/

\section{BIOGRAPHIES}

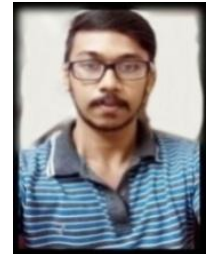

Vishesh $\mathbf{S}$ who hails from Bangalore (Karnataka) has completed B.E in Telecommunication Engineering from VTU, Belgaum, Karnataka in 2015. His research interest includes embedded systems, wireless communication and medical electronics. $\mathrm{He}$ is also the founder and director of the company Konigtronics (OPC) Pvt. Ltd.

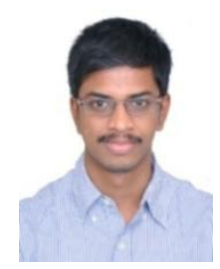

Manu Srinath hails from Bangalore (Karnataka); he has completed B.E in Telecommunication Engineering from VTU, Belgaum, Karnataka. His research interests include networking, image processing and cryptography. $\mathrm{He}$ is the Executive Officer at the company Konigtronics (OPC) Pvt. Ltd.

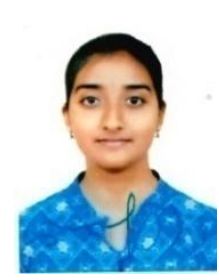

Shruthi Sreeram hails from Bangalore, Karnataka. She is currently pursuing B.E in Electronics and Communication Engineering at BNM Institute of Technology. Her research interests include embedded systems and networking.

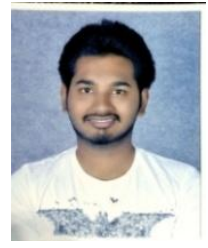

Pratheek Jayanth hails from Bangalore, Karnataka. He is currently pursuing B.E in Electronics and Communication Engineering at BNM Institute of Technology. His research interests include embedded systems, networking and VLSI design.

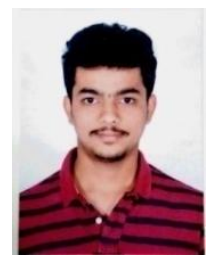

Samarth Bharadwaj DD hails from Bangalore, Karnataka. He is currently pursuing B.E in Information Science Engineering at BNM Institute of Technology. His research interests include cloud computing and software engineering.

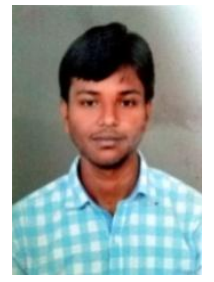

Sanjeev Sanjee Venkatachalapathi hails from Bangalore, Karnataka. $\mathrm{He}$ is currently pursuing B.E in Information Science Engineering at BNM Institute of Technology. His research interests include game theory and artificial intelligence. 